\title{
Assessing potential debris flow runout: a comparison of two simulation models
}

\author{
M. Pirulli ${ }^{1}$ and G. Sorbino ${ }^{2}$ \\ ${ }^{1}$ Department of Structural and Geotechnical Engineering, Politecnico di Torino, Italy \\ ${ }^{2}$ Department of Civil Engineering, University of Salerno, Italy
}

Received: 17 March 2008 - Revised: 26 June 2008 - Accepted: 16 July 2008 - Published: 29 August 2008

\begin{abstract}
In the present paper some of the problems related to the application of the continuum mechanics modelling to debris flow runout simulation are discussed.

Particularly, a procedure is proposed to face the uncertainties in the choice of a numerical code and in the setting of rheological parameter values that arise when the prediction of a debris flow propagation is required.

In this frame, the two codes RASH3D and FLO2D are used to numerically analyse the propagation of potential debris flows affecting two study sites in Southern Italy.

For these two study sites, a lack in information prevents that the rheological parameters can be obtained from the back analysis of similar well documented debris flow events in the area. As a prediction of the possible runout area is however required by decision makers, an alternative approach based on the analysis of the alluvial fans existing at the toe of the two studied basins is proposed to calibrate rheological parameters on the safe side.

From the comparison of the results obtained with RASH3D (where a Voellmy and a Quadratic rheologies are implemented) and FLO2D (where a Quadratic rheology is implemented) it emerges that, for the two examined cases, numerical analyses carried out with RASH3D assuming a Voellmy rheology can be considered on the safe side respect to those carried out with a Quadratic rheology.
\end{abstract}

\section{Introduction}

Many of the world's most devastating landslide disasters, as measured by loss of life and/or economic value, can be attributed to debris flows and their volcanic counterparts called lahars (Jakob and Hungr, 2005). Common dangerous char-

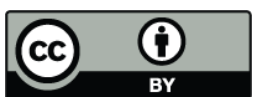

Correspondence to: M. Pirulli

(marina.pirulli@polito.it) acteristics of this type of events are represented by the quite total absence of premonitory signs, their high velocities and long travel distances.

The reduction of losses inferred by debris flows can be pursued by prediction of their velocities and runout distances. Indeed, runout prediction provides a mean of defining the susceptible areas, estimating the debris flows intensity (that is an input of risk studies), and working out the information for the individuation and design of appropriate protective measures. At the same time, reliable predictions of runout can help avoiding exceedingly conservative decisions regarding the urban development of hazardous areas (Cascini et al., 2005).

Debris flows are made up of soil, rock, and water. Their flow characteristics depend on the water content, sediment size and/or sorting, and on the dynamic interaction between the solid and fluid phases. The modelling of such an interaction still remains a quite difficult task and the currently available computational models inevitably rely on simplifying assumptions.

At present, most practical runout predictions are empirical, making use of correlations among historical data (e.g. Corominas, 1996; Zimmermann et al., 1997; Rickenmann, 1999). Though all of these methods are easy to use, they should only be applied to conditions similar to those on which their development is based (Rickenmann, 2005).

A different and promising approach is that based on the continuum numerical modelling, whose models allow determination of the flow parameters and deformation of the mass along the entire path, including deposition (e.g. O'Brien et al., 1993; Iverson and Denlinger, 2001; McDougall and Hungr, 2005).

The numerical codes based on this last approach are at present largely used, even if 1) setting of rheological parameter values for prediction purposes is troublesome, as a lack in information may prevent from obtaining them by resorting to back analyses, and 2) results can be a function of the

Published by Copernicus Publications on behalf of the European Geosciences Union. 
used code and the assumed rheology. In the following, according to McDougall and Hungr (2003), "two-dimensional" and "three-dimensional" broadly denote models that simulate flow across 2-D and 3-D terrain, respectively.

The paper intends to give some guidelines in choosing rheological parameter values when data on historic debris flow events are not available. An approach based on the analysis of the geological and geomorphological settings that characterize a study basin and of the alluvial fans that may exist at the its toe is then proposed to calibrate rheological parameters.

To support this approach and to compare different rheologies, numerical analyses have been carried out for two study sites in Southern Italy affected by debris flows. For both the study sites, a lack in information prevents the calibration of rheological parameters through the back analysis of well documented events in the area but quantitative information to be used for susceptibility and hazard analyses are required by decision makers.

The two continuum mechanics codes RASH3D (Pirulli, 2005; Pirulli et al., 2007) and FLO2D (O'Brien et al., 1993) are then used to simulate the propagation of these two debris flows using the Voellmy and the Quadratic rheology. The obtained results are compared and discussed.

\section{Continuum mechanics modelling}

Numerical models based on continuum mechanics treat the heterogeneous and multiphase moving mass of a debris flow as a continuum. This implies that both the depth $(H)$ and length $(L)$ of the flowing mass are considered to be large compared to the dimensions of the single particles involved in the movement. By adopting this hypothesis, the dynamics of debris flows can be modelled using an "equivalent" fluid, whose rheological properties are such that the bulk behaviour of the numerically simulated flowing mass can approximate the expected bulk behaviour of the real mixture of the solid and fluid phases. The dynamic behaviour of the equivalent fluid can be described by the following mass and momentum conservation laws:

$\nabla \cdot v=0$

$\rho\left(\frac{\partial \boldsymbol{v}}{\partial t}+\boldsymbol{v} \cdot \nabla \boldsymbol{v}\right)=-\nabla \cdot \boldsymbol{\sigma}+\rho \boldsymbol{g}$

where $\boldsymbol{v}(\mathrm{x}, \mathrm{y}, \mathrm{z}, \mathrm{t})=\left(v_{\mathrm{x}}, v_{\mathrm{y}}, v_{\mathrm{z}}\right)$ denotes the three-dimensional velocity vector of the mass in a $(\mathrm{x}, \mathrm{y}, \mathrm{z})$ reference system, $\sigma(\mathrm{x}, \mathrm{y}, \mathrm{z}, \mathrm{t})$ is the Cauchy stress tensor, $\rho$ the mass density, and $\boldsymbol{g}(\mathrm{x}, \mathrm{y}, \mathrm{z})=\left(g_{\mathrm{x}}, g_{\mathrm{y}}, g_{\mathrm{z}}\right)$ is the gravitational acceleration vector in the above mentioned reference system.

\subsection{Depth averaged equations}

If it is assumed that, during debris flow motion, the thickness of the moving mass is much smaller than its length, it is possible to integrate the balance Eqs. (1)-(2) in depth, obtaining the so-called depth averaged continuum flow models (Savage and Hutter, 1989), which can be cast either in Eulerian or Lagrangian form.

Depth averaging allows a complete three dimensional description of the flow to be avoided: changes in the mechanical behaviour within the flow are ignored and the rheology of the flowing material is incorporated into a single term that describes the frictional stress which develops at the interface between the flowing material and the rough surface of the bed path. An interesting description of the rheologies usually adopted to describe debris flows is given in Naef et al. (2006).

Experimental measurements, both on steep slopes in two and three dimensions (e.g. Savage and Hutter, 1989; Gray et al., 1999; Wieland et al., 1999) and on curved beds (e.g. Greve and Hutter, 1993; Greve et al., 1994; Koch et al., 1994), agree relatively well with the prediction of motion and spreading of the mass given by a depth averaged model. As a consequence, starting from the introduction of depth averaged equations in the context of granular flows by Savage and Hutter (1989), numerical models such as FLO2D (O'Brien et al., 1993) and RASH3D (Pirulli, 2005; Pirulli et al., 2007) have been widely implemented.

\section{RASH3D versus FLO2D}

The RASH3D and FLO2D numerical codes, used in the present study, are both based on depth-averaged Eulerian flow models, but they differ in the technique adopted for the numerical implementation of the governing system of Eqs. (1)-(2): a finite volume scheme in RASH3D (Mangeney et al., 2003), and a finite difference scheme in FLO2D (O’Brien et al., 1993).

Both the codes need the pre-event digital elevation model (DEM) of the study area as input data. In FLO2D, the topographic surface is overlaid with a square finite difference grid system and the flow is routed in eight possible flow directions (the four compass directions and the four diagonal directions) (Fig. 1a); in RASH3D, the topography is discretized on a general triangular grid with a finite element data structure. A particular control volume, the median based dual cell, is used to compute the flow in the different flow directions (Audusse et al., 2000; Fig. 1b).

Both the codes also need the definition of the position of the source area of the debris flow as well as the magnitude of the triggered mass. As far as this aspect is concerned, the two codes are different. In FLO2D, an inflow flood hydrograph is required, while in RASH3D, the boundary of the source area and the geometry of the initial volume must be specified. 


\subsection{FLO2D model}

The water flood and mud flow simulation program FLO2D validity has been widely corroborated in time (e.g. Garcia et al., 2004; Bello et al., 2003).

The continuity Eq. (1) and the momentum Eq. (2) are expressed in a depth-averaged way as follows:

$\frac{\partial h}{\partial t}+\frac{\partial\left(h \overline{v_{x}}\right)}{\partial x}+\frac{\partial\left(h \overline{v_{y}}\right)}{\partial y}=i$

$S_{f x}=S_{o x}-\frac{\partial h}{\partial x}-\frac{\overline{v_{x}}}{\mathrm{~g}} \frac{\partial \overline{v_{x}}}{\partial x}-\frac{\overline{v_{y}}}{\mathrm{~g}} \frac{\partial \overline{v_{x}}}{\partial y}-\frac{1}{\mathrm{~g}} \frac{\partial \overline{v_{x}}}{\partial t}$

$S_{f y}=S_{o y}-\frac{\partial h}{\partial y}-\frac{\overline{v_{y}}}{\mathrm{~g}} \frac{\partial \overline{v_{y}}}{\partial y}-\frac{\overline{v_{x}}}{\mathrm{~g}} \frac{\partial \overline{v_{y}}}{\partial x}-\frac{1}{\mathrm{~g}} \frac{\partial \overline{v_{y}}}{\partial t}$

where $S_{f}=\frac{\tau_{y}}{\gamma_{m} h}+\frac{K \eta V}{8 \gamma_{m} h^{2}}+\frac{n^{2} V^{2}}{h^{4 / 3}}$ denotes the depth-averaged flow velocity, $h$ is the flow depth, $i$ is the rainfall intensity on the flow surface and $g$ is the gravity constant. The friction slope components $S_{f x}$ and $S_{f y}$ are written as functions of the bed slope $S_{o x}$ and $S_{o y}$, the pressure gradient and the convective and local acceleration terms. As far as the rheological characteristics of the flowing mass are concerned, FLO2D adopts the quadratic rheological approach proposed by Julien and Lan (1991). The friction slope is therefore provided by the following expression:

$S_{f i(i=x, y)}=\frac{\tau}{\rho \mathrm{g} h}=\frac{\tau_{y}}{\rho \mathrm{g} h}+\frac{K \eta \overline{v_{i}}}{8 \rho \mathrm{g} h^{2}}+\frac{n_{t d}^{2}{\overline{v_{i}}}^{2}}{h^{4 / 3}}$

where $\tau$ is the shear stress, $\tau_{y}$ is the Bingham yield stress, $\eta$ is the Bingham viscosity, $K$ is the flow resistance parameter and $n_{t d}$ is the equivalent Manning coefficient for the turbulent and dispersive shear stress components.

The first and the second terms on the right hand side of Eq. (6) are, respectively, the yield term and the viscous term as defined in the Bingham equation. The last term represents the turbulence contribution (O'Brien et al., 1993).

\subsection{RASH3D model}

The RASH3D code (Pirulli, 2005) is an upgrade of a previously-existing numerical code (SHWCIN) (Audusse et al., 2000; Mangeney et al., 2003) developed by INRIA (Institut National de Recherche en Informatique et en Automatique, France) and IPGP (Institut de Physique du Globe de Paris, France). In order to simulate landslide propagation on a complex three-dimensional topography, it was necessary to upgrade the pre-existing code by

1. reducing mesh-dependency effects through the introduction of an unstructured mesh (i.e. nodes of the mesh cannot have an equal number of adjacent elements),

2. allowing changes of the gravity vector components as a function of the topography and

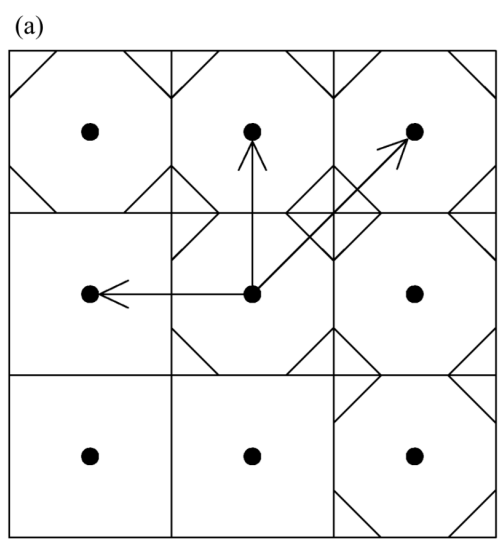

(b)

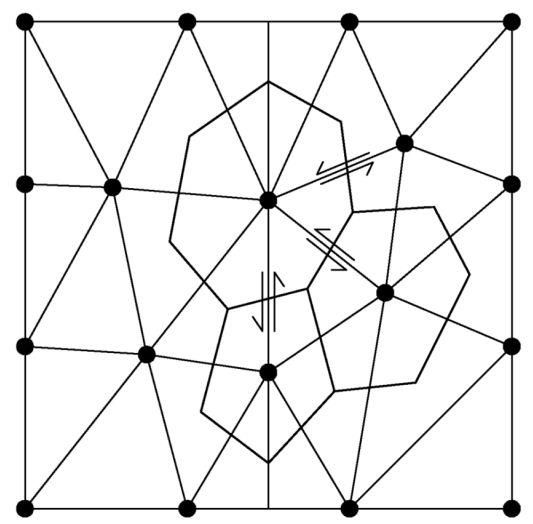

Fig. 1. Conceptual discretisation for the topography and flow (a) FLO2D, and (b) RASH3D.

3. implementing different constitutive laws (Pirulli, 2005).

The modified code (RASH3D) validity has been corroborated through simulations of laboratory tests (e.g. Pirulli, 2005) and back analyses of real cases (e.g. Pirulli et al., 2007; Pirulli and Mangeney, 2008).

In RASH3D the continuity Eq. (1) and the momentum Eq. (2) are depth-averaged, in a reference system having the $z$ direction aligned with the local bed-normal direction, and expressed as follows:

$\frac{\partial h}{\partial t}+\frac{\partial\left(h \overline{v_{x}}\right)}{\partial x}+\frac{\partial\left(h \overline{v_{y}}\right)}{\partial y}=0$

$\frac{\partial\left(h \overline{v_{x}}\right)}{\partial t}+\frac{\partial\left(h \overline{v_{x}^{2}}\right)}{\partial x}+\frac{\partial\left(h \overline{v_{x} v_{y}}\right)}{\partial y}+\frac{\partial}{\partial x}\left(g_{z} \frac{h^{2}}{2}\right)$

$=g_{x} h-g h S_{f x} \frac{\overline{v_{x}}}{\|\overline{\boldsymbol{v}}\|}$ 


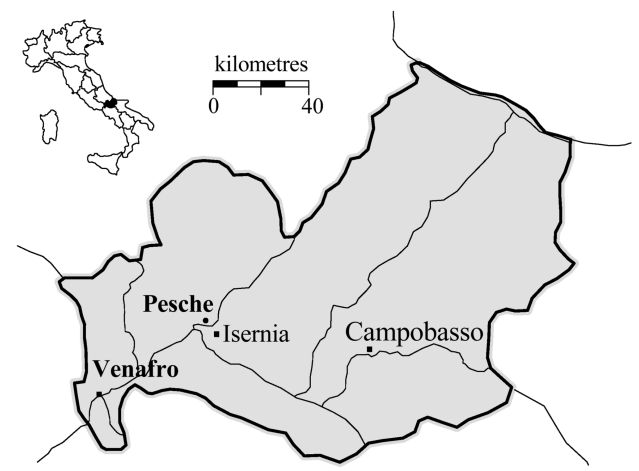

Fig. 2. The villages of Pesche and Venafro in the Molise Region (Southern Italy).

$$
\begin{aligned}
& \frac{\partial\left(h \overline{v_{y}}\right)}{\partial t}+\frac{\partial\left(h \overline{v_{x} v_{y}}\right)}{\partial x}+\frac{\partial\left(h \overline{v_{y}^{2}}\right)}{\partial y}+\frac{\partial}{\partial y}\left(g_{z} \frac{h^{2}}{2}\right) \\
= & g_{y} h-g h S_{f y} \frac{\overline{v_{y}}}{\|\overline{\boldsymbol{v}}\|}
\end{aligned}
$$

where $S_{f}=\frac{\tau_{y}}{\gamma_{m} h}+\frac{K \eta V}{8 \gamma_{m} h^{2}}+\frac{n^{2} V^{2}}{h^{4 / 3}}$ denotes the depth-averaged flow velocity, $h$ is the flow depth, $\mathrm{g}$ is the gravity constant, and $S_{f x}$ and $S_{f y}$ are the friction slope components.

Only the frictional rheology was originally implemented in the RASH3D code. But, analyses of debris flows carried out with a frictional rheology frequently result in a large overestimation of velocity and sometimes in an unrealistic behaviour of the mass (e.g. Pirulli and Sorbino, 2006).

Since the Voellmy rheology, which was initially developed for snow avalanche propagation, has successfully been applied to debris flow propagation by many Authors (e.g. Rickenmann and Koch, 1997), it has been implemented in RASH3D.

The Voellmy flow relation consists of a turbulent term, which accounts for velocity-dependent friction losses, and a Coulomb or basal friction term. When adopting the Voellmy law, the friction slope components are the following:

$S_{f i(i=x, y)}=\cos \alpha \tan \varphi+\frac{{\overline{v_{i}}}^{2}}{h \xi}$

where $\alpha$ is the inclination of the bed from horizontal, $\varphi$ is the basal friction angle, $\xi$ is the turbulence coefficient; the other terms have already been defined.

In order to verify whether RASH3D and FLO2D are able to give similar results when the same rheology is applied, the quadratic rheology (see Eq. 6) was also implemented in RASH3D.
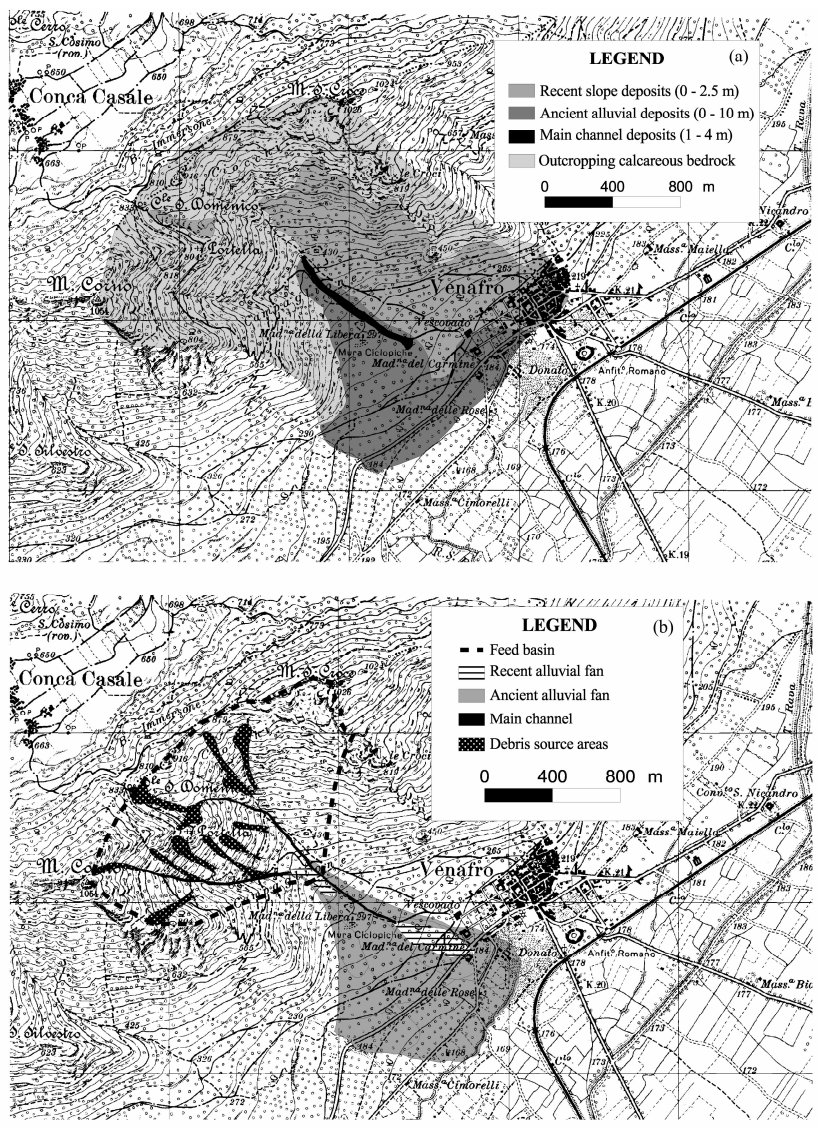

Fig. 3. The Venafro study site; (a) geological map; (b) geomorphological map.

\section{Description of the study areas}

The villages of Pesche and Venafro, located in the Molise Region (Southern Italy), are two geographical areas where potential debris flows hang over both developing and already urbanized areas (Fig. 2).

The geological and geomorphological setting of both the sites (Figs. 3 and 4) is typical of the carbonatic-dolomitic mountain chains of the Southern Italian Appennines, where the morphology is made of high peaks and steep slopes with sub-vertical walls. The continuity of the slopes is often interrupted by deep channels located along the principal and secondary structural lineaments. These channels have a Vshaped or rectangular cross-section. They are frequently filled by coarse debris which originated from the climatic erosion of the outcropping rocks in the upper parts of the basins, as well as from shallow landslides occurring in the weathered and fractured rocks that form the flanks of the channels.

The debris filling the channels existing in the two study areas is mainly composed of coarse deposits with boulders and fluvial gravelly-sand deposits, these latter having a percentage in volume not higher than $30 \%$. In the urbanised valleys, 
Table 1. Main morphometric characteristics of the two study basins.

\begin{tabular}{lll}
\hline & Pesche & Venafro \\
\hline Feed Basin & $0.7 \mathrm{~km}^{2}$ & $1.4 \mathrm{~km}^{2}$ \\
Mean slope angle of feed basin & $21^{\circ}$ & $32.5^{\circ}$ \\
Main channel length & $1.4 \mathrm{~km}$ & $1.3 \mathrm{~km}$ \\
Mean slope angle of main channel & $15^{\circ}$ & $18^{\circ}$ \\
Recent fan area & $99054 \mathrm{~m}^{2}$ & $50879 \mathrm{~m}^{2}$ \\
Mean slope angle of recent fan & $4.5^{\circ}$ & $8^{\circ}$ \\
\hline
\end{tabular}

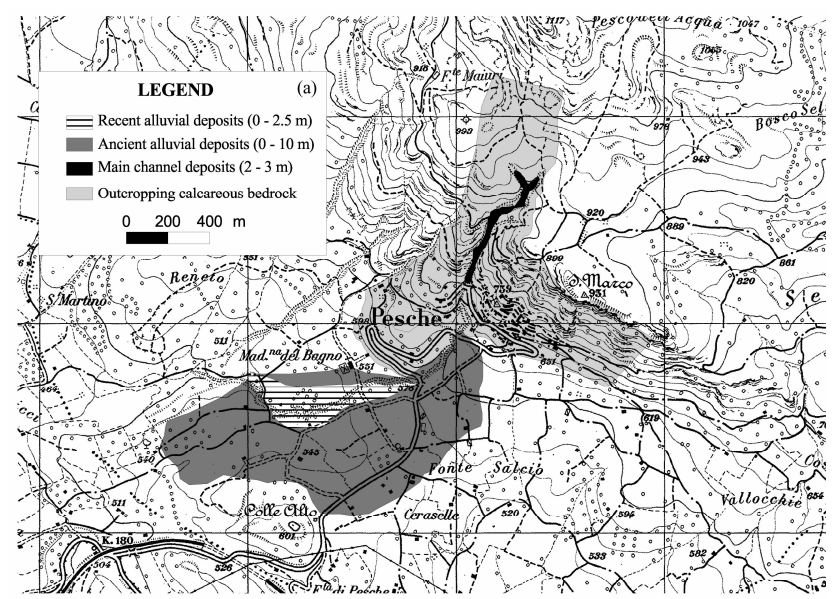

located at the toe of the two study sites, alluvial fans of various extension and age can be recognised, and they testify the systematic occurrence of debris flow phenomena. Geological and geomorphological investigations have allowed a detailed mapping of the extents of the past debris-flow deposits (Figs. 3 and 4), providing a distinction between recent and ancient zones of the alluvial fans. The ancient zones of the alluvial fans represent the deposition zone of ancient debris flow events, as testified by the sediments exposed in medial and distal fan sections belonging to the Early-Middle Holocene (i.e. 10000-3500 yr BP). The recent zones of alluvial fans, mostly located at proximal fan sections, are conversely formed by younger sediments of late Holocene age (3500 yr BP to present) and also represent the deposition zone of recent debris flow events.

The main morphometric characteristics of the two basins in which potential debris flows can occur are summarised in Table 1.

Particularly, the Venafro's site (Fig. 3) is represented by a large basin having an area of about $1.4 \mathrm{~km}^{2}$. Such basin has high slope angles (about 40 degrees) in its upper part and gently degrades downslope towards the so-called Venafro Plain. The drainage network is not well developed and it is characterised by the presence of a main channel having a length of about $1.3 \mathrm{~km}$ and a mean slope of 18 degrees. This channel is filled with loose material with a thickness in the range of $1.0-4.0 \mathrm{~m}$, produced by erosional phenomena and shallow landslides affecting the outcropping calcareous rocks in the upper part of the basin. According to the geomorphological analyses, this loose material, whose volume estimation is of about $78000 \mathrm{~m}^{3}$, represents a potential source for debris flow events. At the toe of the slope, an alluvial fan apparatus can be recognised. On the basis of geomorphological analyses, this last is mainly formed by an ancient part having a maximum thickness of $10 \mathrm{~m}$. This ancient alluvial fan is covered along its north-eastern side, by a recent alluvial fan having an area of $50879 \mathrm{~m}^{2}$ and a volume of about $100000 \mathrm{~m}^{3}$.

In Pesche the basin has an extension of about $0.7 \mathrm{~km}^{2}$ and is characterised by a deep channel with a steep inner gorge (Fig. 4). Field surveys revealed, in the upper part of the channel and along the gorge, the presence of a loose material with

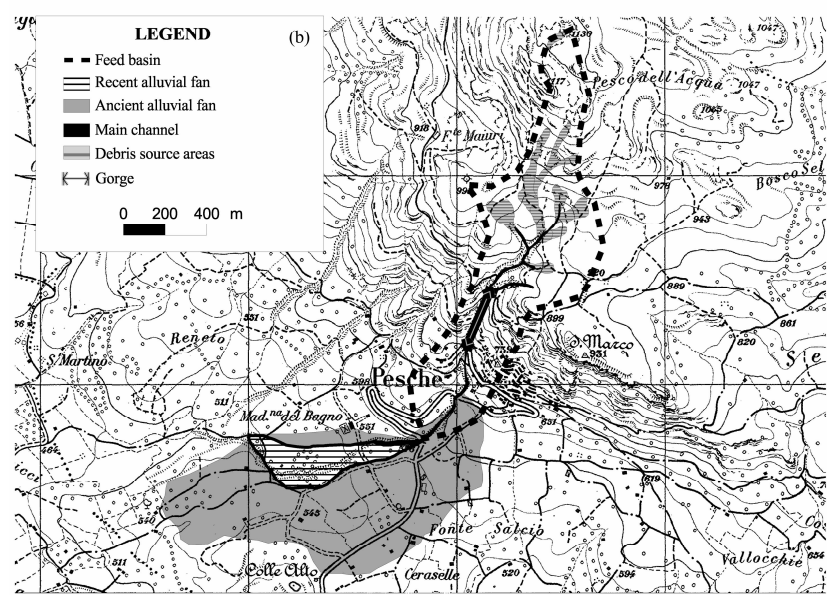

Fig. 4. The Pesche study site; (a) geological map; (b) geomorphological map.

a thickness in the range of 2.0-3-0 m. This loose deposit, having an estimated volume of about $79500 \mathrm{~m}^{3}$, represents the present potential source material of a debris flow.

Analogously to the Venafro's site, at the toe of the main channel, the presence of ancient and recent alluvial fans can be recognised. Particularly, the recent alluvial fan has an area of $99054 \mathrm{~m}^{2}$ and an estimated volume of $190000 \mathrm{~m}^{3}$.

\section{Numerical model settings and calibration criteria}

Three steps are necessary to run numerical analyses with both the codes:

1. to upload the topography of the study area as a DEM (Digital Elevation Model),

2. to determine the initial volume, and

3. to define guidelines for the rheological parameter calibration.

A DEM based on 1:5000 maps, obtained from photogrammetric analyses, was available for each of the study sites. A 


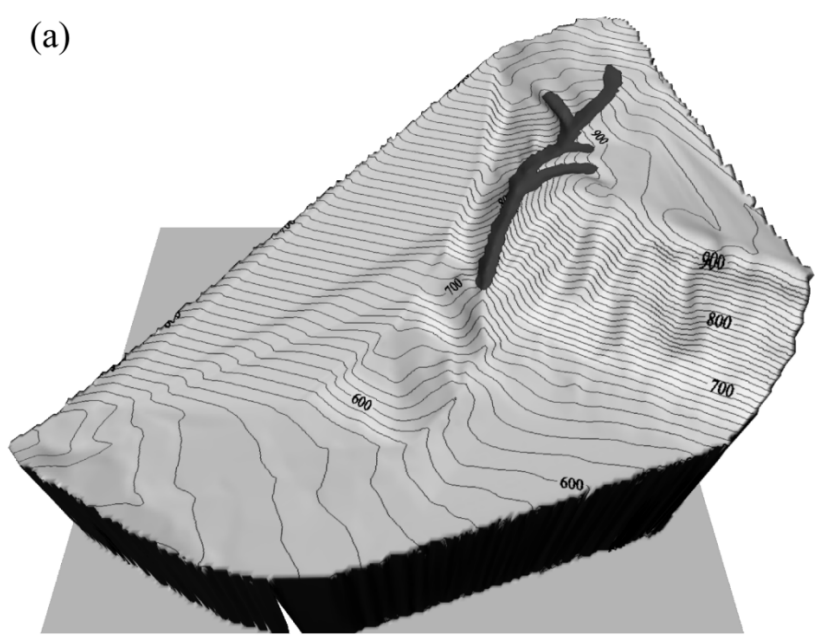

(b)

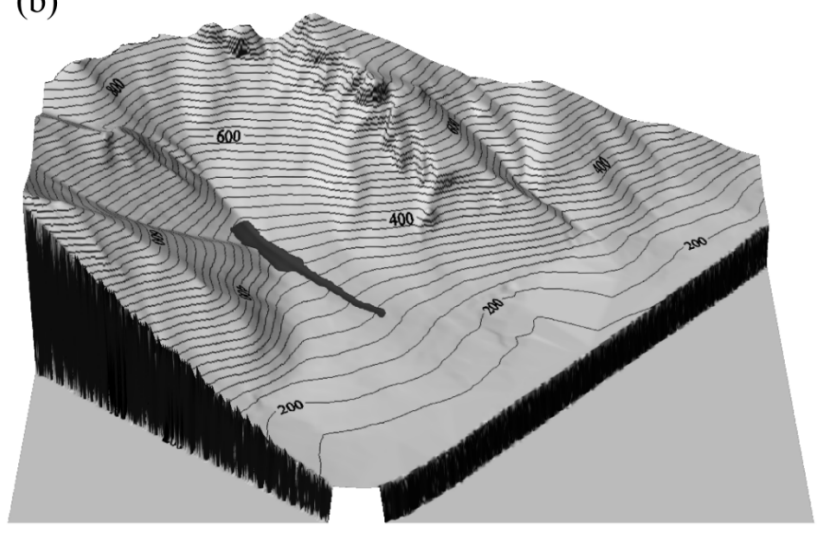

Fig. 5. Geometrical models used in RASH3D (a) Pesche; (b) Venafro. The dark grey areas indicate the considered triggering volume.

5-m topographic grid able to adequately represent the analysed areas was then used for numerical modelling.

In order to take into account the worst-case scenarios for both the study areas, the whole loose material existing in the analysed basins was considered as triggering volume.

Using RASH3D, the triggering volumes were defined in accordance with the spatial distribution of the material as surveyed on site. The geometrical models related to the volumes quoted in Table 2 were then obtained (Fig. 5).

As for the analyses carried out with FLO2D, rain or discharge data, to evaluate the rain that had triggered the past events, were not available for any of the studied areas.

A triangular-shaped input hydrograph was therefore hypothesized. The height of the input hydrograph coincides with the peak discharge, $Q_{p}$, and was estimated using the empirical relationship proposed by Rickenmann (1999):

$Q_{p}=0.1 V^{5 / 6}$

that relates the peak discharge, $Q_{p}\left(\mathrm{~m}^{3} / \mathrm{s}\right)$, of a debris flow and the debris flow volume, $V\left(\mathrm{~m}^{3}\right)$ (Table 2).

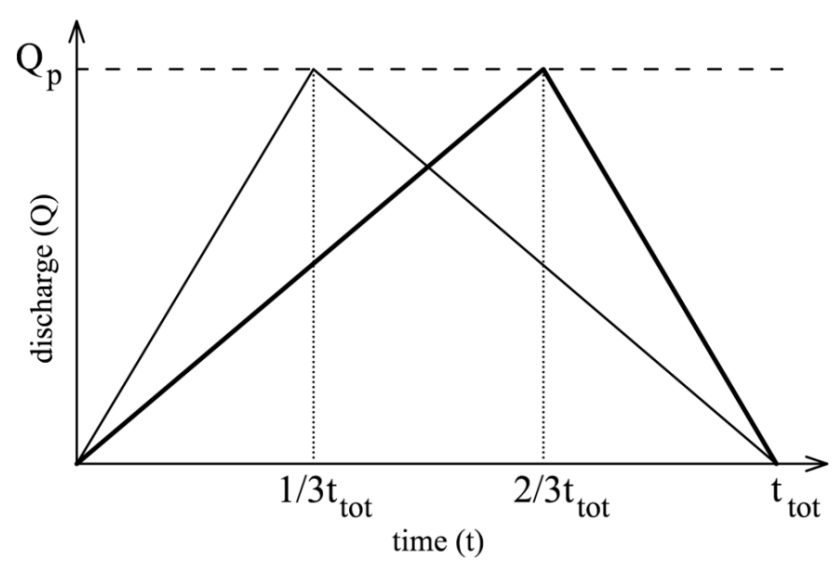

Fig. 6. Definition of the input hydrograph in the FLO2D analyses.

Table 2. Initial volumes and hydrograph for the two study areas.

\begin{tabular}{lccc}
\hline Study & $\begin{array}{c}\text { Initial volume } \\
(\mathrm{RASH} 3 \mathrm{D})\end{array}$ & \multicolumn{2}{c}{$\begin{array}{c}\text { Initial hydrograph } \\
(\text { FLO2D) }\end{array}$} \\
area & $V\left(\mathrm{~m}^{3}\right)$ & $Q_{p}\left(\mathrm{~m}^{3} / \mathrm{s}\right)$ & $t_{\text {tot }}$ (hours) \\
\hline Pesche & 79500 & 1207.8 & 0.037 \\
Venafro & 78000 & 1188.8 & 0.036 \\
\hline
\end{tabular}

The base of the input hydrograph coincides with the time duration, $t_{\text {tot }}$, estimated by multiplying the volume, $V$, by 2 and dividing by the peak discharge, $Q_{p}$. The computed values are quoted in Table 2.

Two different input hydrograph, in which the peak discharge $Q_{p}$ is attained at a time values $t_{p}$ equal to $1 / 3 t_{\text {tot }}$ and $2 / 3 t_{\text {tot }}$, respectively, were adopted in the analyses (Fig. 6).

The setting of rheological parameter values remains the last task to face but it is the major challenge when potential events are investigated.

When the potential event is in a basin where similar well documented events already occurred, these latter can be used to run some back-analyses and calibrate rheological parameters. Reasonable confidence limits have obviously to be applied in using these parameters for prediction purposes (McDougall et al., 2008).

For the two cases analysed in the present paper, this procedure is not practicable due to the absence of adequate data on the historical debris flow events occurred in both the study sites. Not with standing this, in order to provide some quantitative elements for susceptibility analyses related to the occurrence of potential debris flow phenomena, an alternative way is then pursued.

Considering that, for a given torrent channel and fan topography, larger flows tend to result in longer travel distance 
Table 3. Calibration of rheological parameters. The best fit data for the Quadratic and the Voellmy rheologies are in bold in case of Venafro and in italic in case of Pesche.

\begin{tabular}{llll}
\hline \multicolumn{2}{c}{$\begin{array}{c}\text { RASH3D } \\
\text { Voellmy }\end{array}$} & $\begin{array}{c}\text { FLO2D - RASH3D } \\
\text { Quadratic }\end{array}$ \\
$\mu(=\tan \varphi)(-)$ & $\xi\left(\mathrm{m} / \mathrm{s}^{2}\right)$ & $\tau_{y}(\mathrm{kPa})$ & $\eta(\mathrm{Pa} \cdot \mathrm{s})$ \\
\hline 0.01 & 100 & 1.2 & 20 \\
0.01 & 200 & 1.5 & 10 \\
0.01 & 500 & 1 & 10 \\
0.05 & 100 & 0.7 & 10 \\
0.05 & 200 & 0.7 & 5 \\
0.05 & 1000 & 0.7 & 15 \\
0.1 & 100 & & \\
0.1 & 200 & & \\
0.1 & 500 & & \\
0.1 & 1000 & & \\
0.12 & 1000 & & \\
0.15 & 1000 & & \\
0.2 & 1000 & & \\
\end{tabular}

than smaller flows having similar material properties (Rickenmann, 2005), the distal point of the existing alluvial fans can give an indication of the distance reached by the largest mass released in the past from each of the considered basins. Analysing the recent alluvial fans existing at the toe of the two studied basins, it emerged that each of them is the deposition zone of debris flow events occurred during the last 3500 years. On the basis of geological and geomorphological studies it can be assumed that the current loose deposits filling the source zones of potential debris flows phenomena have volumes smaller than or, at least, equal to the largest volume involved in a single debris flow event occurred during the last 3500 years.

On the basis of these considerations, numerical analyses are carried out calibrating rheological parameters in order to obtain a travel distance of the flowing mass equal to the distal point of the observed recent alluvial fans. In this way, the calibrated rheological parameters can be considered on the safe side in terms of susceptibility analysis and, in the meantime, they can be used in defining hazardous areas and working out important information for land management.

To this aim results obtained with RASH3D and FLO2D assuming a Voellmy or a Quadratic rheology are presented and discussed in the following.
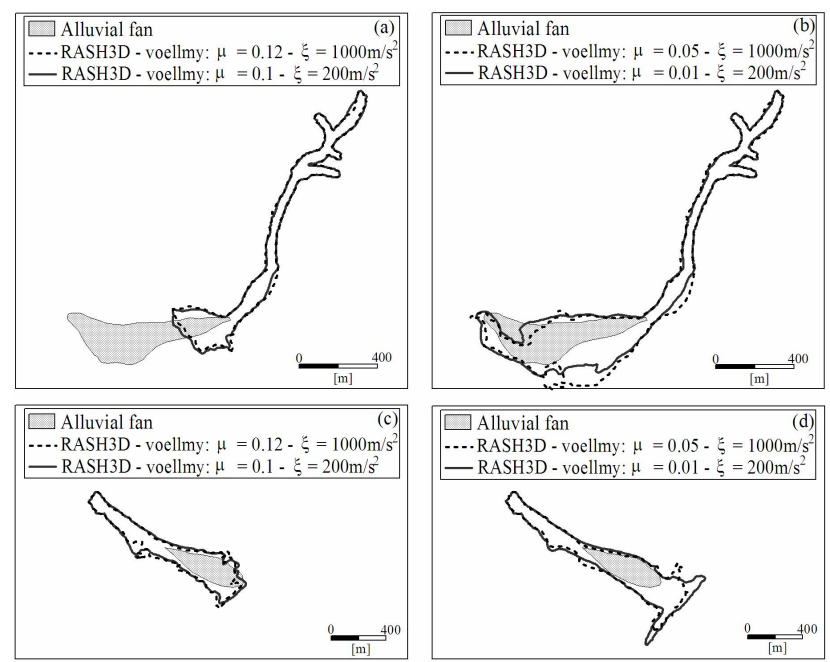

Fig. 7. Results obtained for both the sites using the calibrated rheological parameters. (a)-(b) Pesche case; (c)-(d) Venafro case.

\section{Application of the models and discussion of the results}

6.1 Simulations of the Pesche and Venafro events with a Voellmy rheology

The analyses with a Voellmy rheology were carried out using the RASH3D code.

A first set of values for the rheological parameters was obtained from the back-analysis of some historical debris flows in North Europe (Rickenmann et al., 2006), in Hong Kong (courtesy of Civil Engineering and Development Department of the Government of the Hong Kong) and in Southern Italy (Revellino et al., 2004).

Considering North Europe cases and Southern Italy cases, the range of rheological parameters is: friction coefficient, $\mu$, between 0.01 and 0.1 , and turbulence coefficient, $\xi$, between 100 and $200 \mathrm{~m} / \mathrm{s}^{2}$. While, for Hong Kong cases, it is suggested: friction coefficient, $\mu$, between 0.1 and 0.2 , and turbulence coefficient, $\xi$, between 500 and $1000 \mathrm{~m} / \mathrm{s}^{2}$. Consequently, a sensitivity study was made changing the friction coefficient, $\mu$, between 0.01 and 0.2 , and the turbulence coefficient, $\xi$, between 100 and $1000 \mathrm{~m} / \mathrm{s}^{2}$ (Table 3), until a good agreement between the longitudinal extension of simulated and observed alluvial fans was obtained.

The best match of both the recent alluvial fans can be found for different couples of rheological values. In the Pesche case, good results were obtained with

1. $\mu=0.05$ and $\xi=1000 \mathrm{~m} / \mathrm{s}^{2}$, and

2. $\mu=0.01$ and $\xi=200 \mathrm{~m} / \mathrm{s}^{2}$.

While, in the Venafro case:

1. $\mu=0.12$ and $\xi=1000 \mathrm{~m} / \mathrm{s}^{2}$, and

2. $\mu=0.1$ and $\xi=200 \mathrm{~m} / \mathrm{s}^{2}$ gave satisfactory numerical results.. 

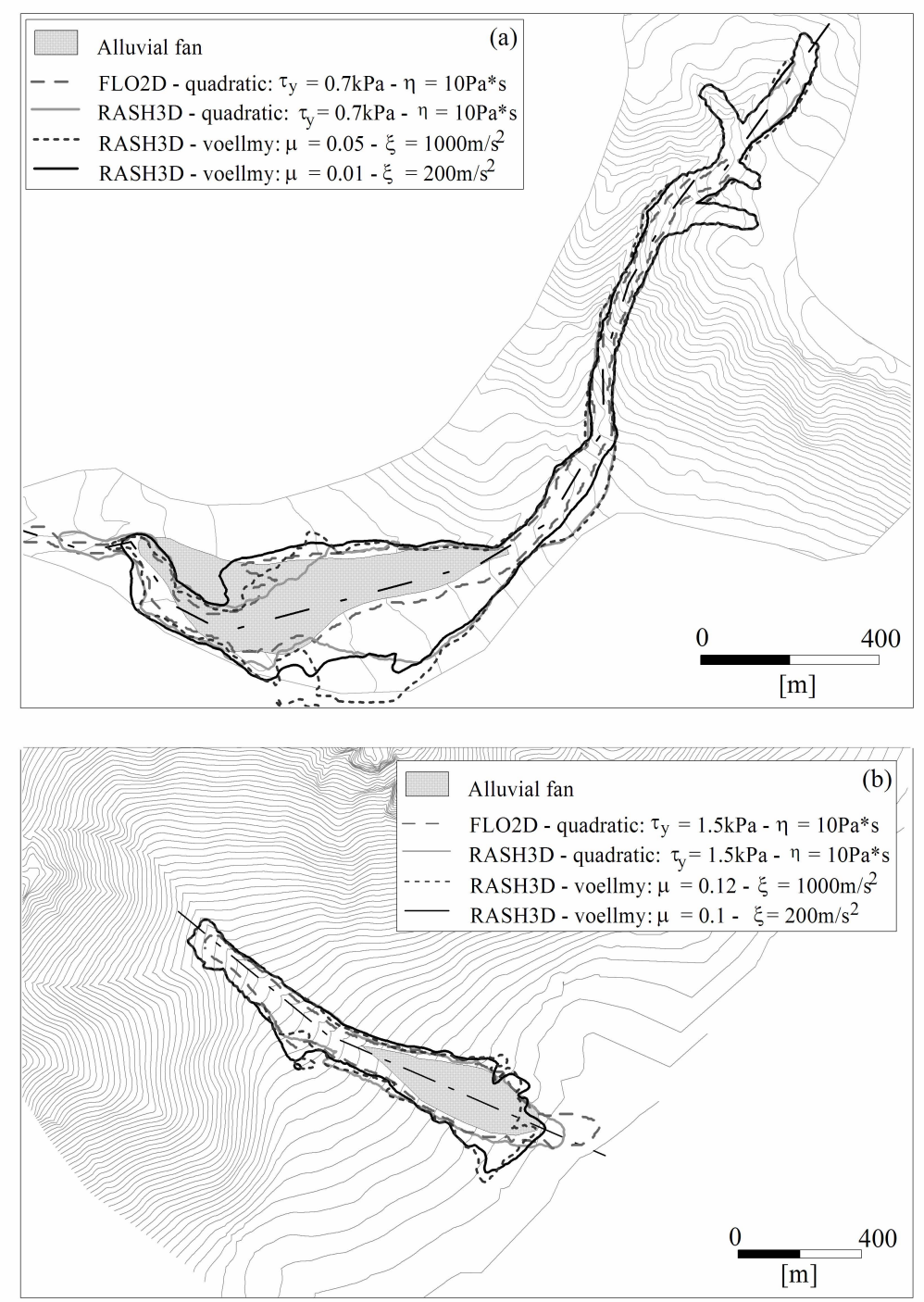

Fig. 8. Deposition patterns obtained with the two assumed rheologies. (a) Pesche; (b) Venafro.

As showed in Fig. 7, using in Venafro the rheological parameters calibrated for Pesche and vice versa did not give satisfactory results .

The analysis of the propagation with the couples of calibrated rheological parameters evidenced difference in reached maximum velocity (Tab. 4), run out area being similar (Fig. 8). In both the analysed cases, higher maximum velocities were reached where a $\xi=1000 \mathrm{~m} / \mathrm{s}^{2}$ was assumed (Table 4).

In Pesche, both the numerical simulations gave, with respect to the existing fan:

1. a much larger lateral spreading just below the fan apex,

2. a lateral contraction of the spreading area in the distal part reached by the mass, and
3. a flow that generally follows the downstream direction of the channel that crosses longitudinally the alluvial fan (Fig. 8a).

In Venafro, a quite good approximation of the fan was obtained along the propagation path but the mass gave a runout area in the distal part whose shape is quite different from that of the existing fan: a lateral spread was obtained instead of a lobate front (Fig. 8b).

It can be finally stated that a mass spreading can be observed in both the analysed cases: along the propagation path for Pesche and in the final propagation path for Venafro. 
6.2 Simulations of the Pesche and Venafro events with a quadratic rheology

To carry out analyses with a quadratic rheology, the FLO2D code was first used.

In the case of Pesche, a starting value of the Bingham parameter $\tau_{y}\left(=\gamma \cdot h^{\prime} \cdot \mu\right)$ was obtained using the calibrated friction coefficient value $(\mu=0.05)$ previously obtained for the Voellmy rheology and, in consideration of the characteristics of the analysed site, a mean depth of the flow $\left(h^{\prime}\right)$ equal to $1.2 \mathrm{~m}$ together with a unit weight $(\gamma)$ equal to $20 \mathrm{kN} / \mathrm{m}^{3}$. A tentative $\tau_{y}$ value was therefore set equal $1.2 \mathrm{kPa}$. The dynamic viscosity, $\eta$, was initially deduced from literature and assumed equal to $20 \mathrm{~Pa} \cdot \mathrm{s}$. The equivalent Manning coefficient, based on parametric analyses, was assumed equal to 0.04 , while a K-value of 2480 was used, as suggested in the FLO2D manual, for a rough surface on an alluvial fan.

Changing only the $\tau_{y}$ and $\eta$ parameters, the best approximation of the distal point of the recent alluvial fan was obtained setting $\tau_{y}=0.7 \mathrm{kPa}$ and $\eta=10 \mathrm{~Pa} \cdot \mathrm{s}$ (Table 3 ).

As in the case of the Voellmy rheology, the simulated flow

1. follows the downstream direction of the channel that crosses longitudinally the alluvial fan and

2. contracts in the distal part of the path of propagation. Even if less pronounced, the quadratic rheology gives as the Voellmy rheology a lateral spreading of the mass just below the fan apex (Fig. 8a).

In the Venafro case, the FLO2D analyses were initially carried out by assuming the best fit values previously obtained for the quadratic rheology in the Pesche case ( $\tau_{y}=0.7 \mathrm{kPa}$ and $\eta=10 \mathrm{~Pa} \cdot \mathrm{s}$ ). But, a new calibration of parameters was necessary. The best simulation was obtained with a value of the Bingham parameter $\tau_{y}$ higher than the initial one (Table 3). The calibrated quadratic rheological parameters gave

1. a flow that follows the existing alluvial fan in a close manner and

2. a deposit whose distal part has a lobate shape, as observed in the existing alluvial fan (Fig. 8b).

No significant differences were observed, for both the studied areas, in the FLO2D results when the two previously referred time values $t_{p}$ that define the input hydrograph were varied.

In order to properly compare the results obtained with the two codes, numerical analyses with a quadratic rheology were also performed with RASH3D for both study areas. The rheological parameter values calibrated with FLO2D were then assumed in RASH3D.

The final deposition patterns obtained with the two codes are compared for Pesche and Venafro in Fig. 8a and b, respectively. It can be observed that, as far as the spreading of
Table 4. Maximum numerical velocity reached during propagation as a function of assumed rheological parameters.

\begin{tabular}{|c|c|c|c|}
\hline \multirow{2}{*}{ Site } & \multicolumn{2}{|c|}{ Voellmy rheology } & \multirow{2}{*}{$\overline{\mathbf{v}}_{\max }(\mathrm{m} / \mathrm{s})$} \\
\hline & $\mu(=\tan \varphi)(-)$ & $\xi\left(\mathrm{m} / \mathrm{s}^{2}\right)$ & \\
\hline \multirow[t]{4}{*}{ Pesche } & 0.01 & 200 & 17.4 \\
\hline & 0.05 & 1000 & 27.7 \\
\hline & 0.1 & 200 & 15.7 \\
\hline & 0.12 & 1000 & 25.7 \\
\hline \multirow[t]{4}{*}{ Venafro } & 0.01 & 200 & 11.8 \\
\hline & 0.05 & 1000 & 20.3 \\
\hline & 0.1 & 200 & 10.7 \\
\hline & 0.12 & 1000 & 16.5 \\
\hline
\end{tabular}

the deposition patterns are concerned, rheological parameter values being equal, the RASH3D code gives about the same travel distance as FLO2D but it usually provides a larger lateral spreading of the mass.

6.3 Analysis of the maximum and final deposit depth distribution

A comparison among the distributions of the maximum depths along the propagation paths, obtained using the quadratic rheology in both the two codes and the Voellmy rheology only in RASH3D, is here made. This comparison was performed for both study sites with reference to the longitudinal sections taken along the whole propagation path (long-dash dot line in Fig. 8a and b). The results are shown in Fig. 9.

In terms of quadratic rheology, although RASH3D, compared to FLO2D, slightly underestimated the maximum depths, the two codes provide about the same trend of the maximum depths distribution along the whole propagation path.

As far as the Voellmy rheology is concerned, the RASH3D results underline that the trend of the maximum depths computed at the downstream end of the deposition patterns does not change significantly as a function of the assumed rheology in either of the considered cases (Fig. 9). The main differences, as previously mentioned, concern the larger areal mass spreading given by the Voellmy rheology (Fig. 8a-b)

Since the maximum depth profiles did not give an exhaustive explanation of the differences between the behaviour of the mass with a Voellmy rheology with respect to a quadratic rheology, a comparison was made between the final deposit profiles provided by the two rheologies. This comparison concerns only the results obtained with RASH3D.

Figure 10 shows the final deposit profiles obtained along the same longitudinal sections considered in Fig. 9.

In both the considered sites, the quadratic rheology resulted in a higher longitudinal spreads of the mass along the whole longitudinal propagation path, with lower deposit 

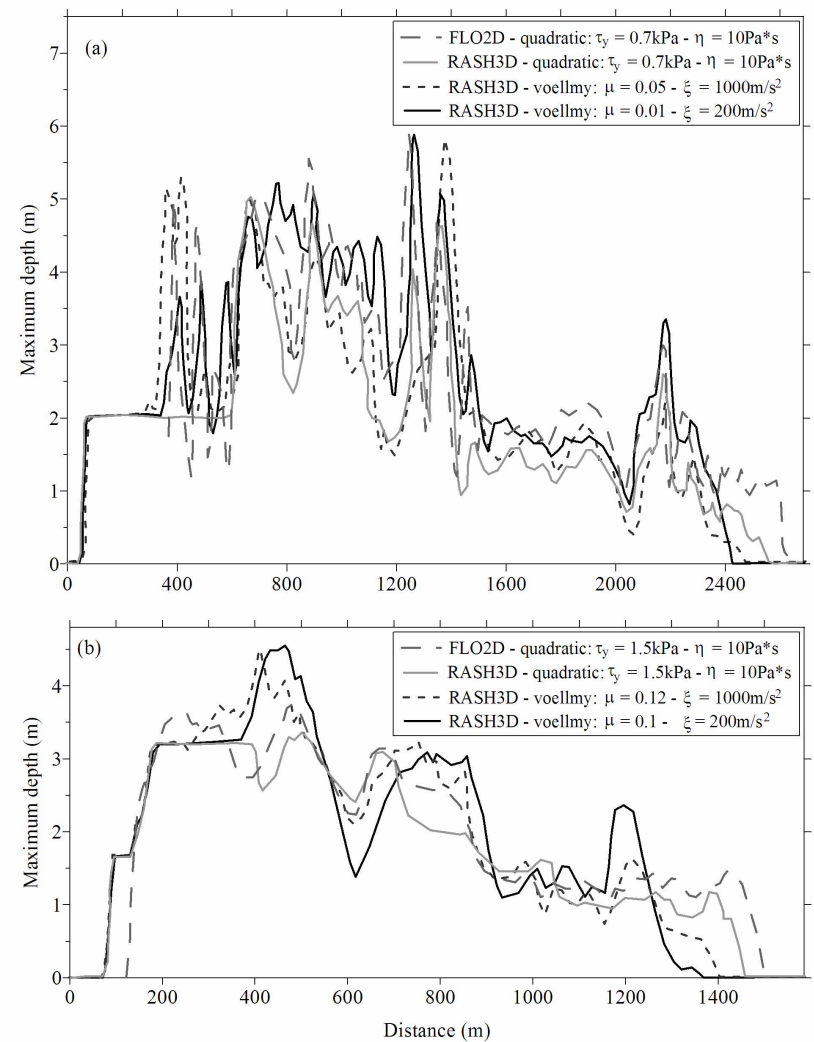

Fig. 9. Maximum depth reached by the mass along the propagation path, (a) the Pesche site; (b) the Venafro site. The profile position is given with a long-dash dot line in Fig. 8a and b, respectively.

depths next to the runout distal point. On the other hand, moving from $\xi=200 \mathrm{~m} / \mathrm{s}^{2}$ to $\xi=1000 \mathrm{~m} / \mathrm{s}^{2}$, the Voellmy rheology concentrates the mass in the distal part of the deposition pattern and the proximal part of the pattern remains mainly free of deposited mass .

\section{Conclusions}

The two codes RASH3D and FLO2D, based on a continuum mechanics approach, have been used to numerically analyse the propagation of two potential debris flows, located respectively at Pesche and Venafro, Southern Italy.

For these two cases, a lack in information has prevented that rheological parameters were obtained from the back analysis of similar well documented events in the area. As a prediction of the possible runout area is, however, required by decision makers, an alternative approach based on the analysis (a) of the geological and geomorphological settings that characterize the two study basins, (b) of the alluvial fans existing at their respective toe and (c) of the rheological parameter values obtained from the literature, when the backanalysis of similar historical events are carried out, have been proposed to calibrate rheological parameters for the two study sites.
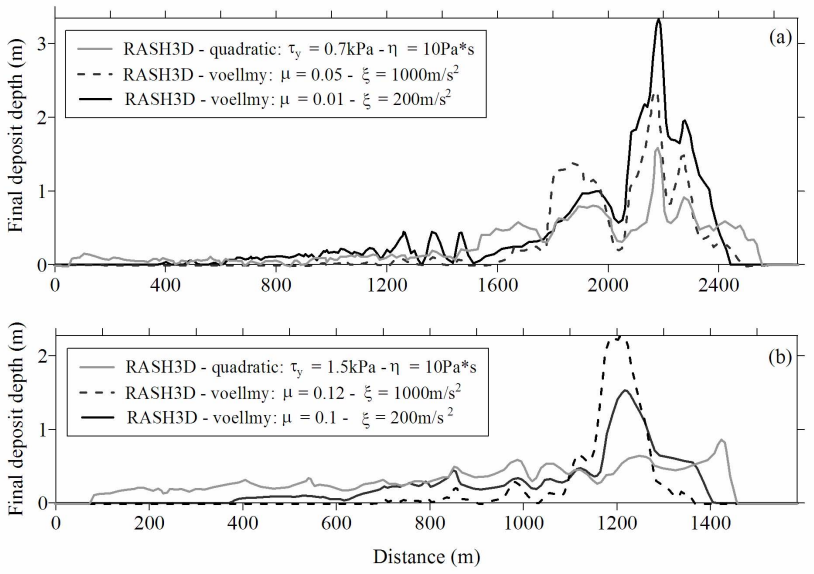

Fig. 10. Final deposit depth considering the whole propagation path, (a) the Pesche site; (b) the Venafro site. The profile position is given with a long-dash dot line in Fig. 8a and b, respectively.

From the results obtained with RASH3D and FLO2D assuming a Voellmy or a Quadratic rheology it emerges that:

1. Even if FLO2D and RASH3D have a different initiation mechanism (hydrograph vs. debris volume), it can be observed that, by adopting the same calibrated Quadratic rheological parameters and by relating the peak discharge (FLO2D) and the triggering volume (RASH3D) with the Rickenmann's formula, the two codes give a similar runout for both the study sites. Differences between the two codes concern a larger lateral spreading of the mass and underestimation of velocities provided by RASH3D compared to FLO2D;

2. Rheology being unchanged (e.g. Voellmy rheology), a similar runout area can be obtained with different couples of rheological parameters but differences emerge in term of final mass distribution, velocity and runout duration;

3. Results obtained with the Quadratic rheology provide a better simulation of the area and shape of the existing alluvial fan than that obtained by the Voellmy rheology. In fact, by adopting a Voellmy rheology, a later spreading of the mass just below the apex of the fan, in the Pesche case, and in the distal zone, in the Venafro case, can be observed.

4. Maximum depths reached by the mass during propagation present the same trend independently from the assumed rheology.

On the base of observations (1) and (3) it can be finally stated that for Pesche and Venafro land management purposes numerical analyses carried out with RASH3D assuming a Voellmy rheology allow to obtain results that are on the safe side. This conclusion cannot at the moment be generalized. On the contrary, the use of more than one code and rheology can be recommended. 
Acknowledgements. The authors wish to thank L. Cascini and C. Scavia for the fruitful discussions and suggestions on the development of the research and A. Mangeney and M.-O. Bristeau for having offered the use of the SHWCIN code and for having helped solve some fundamental numerical problems.

Edited by: T. Glade

Reviewed by: B. McArdell and another anonymous referee

\section{References}

Audusse, E., Bristeau, M. O., and Perthame, B. T.: Kinetic schemes for Saint-Venant equations with source terms on unstructured grids, Institut National de Recherche en Informatique et en $\mathrm{Au}-$ tomatique, Report 3989, LeChesnay, France, 2000.

Bello, M. E., O’Brien, J. S., Lopez, J. L., and Garcìa-Martinez, R.: Simulation of flooding and debris flows in the Cerro Grande River, In: Proc. 3rd Int. Conf. on Debris flow hazards mitigation: mechanics, prediction, and assessment, edited by: Rickenmann, D. and Chen, C., Millpress, Rotterdam, 2003.

Cascini, L., Bonnard, C., Corominas, J., Jibson, R., and MonteroOlarte, J.: Landslide hazard and risk zoning for urban planning and development (State of the Art Report), In: Proc. International conference on landslide risk management, edited by: Hungr, O., Fell, R., Couture, R., and Eberhardt, E., A. A. Balkema, Rotterdam, The Netherlands, 2005.

Corominas, J.: The angle of reack as a mobility index for small and large landslides, Can. Geotech. J., 33, 260-271, 1996.

Garcìa, R., Rodrìguez, J. J., and O'Brien, J. S.:Hazard zone delineation for urbanized alluvial fans, in: P. World Water and Environmental Resources Congress - Arid Lands Symposium, 27 June-1 July 2004, ASCE, Reston, Va., USA, 1-10, 2004.

Gray, J. M. N. T., Wieland, M., and Hutter, K.: Gravity-driven free surface flow of granular avalanches over complex basal topography, P. Roy. Soc. London A, 455, 1841-1874, 1999.

Greve, R. and Hutter, K.: Motion of a granular avalanche in a convex and concave curved chute: experiments and theoretical predictions, Phil. Trans. Roy. Soc. London A, 342, 573-600, 1993.

Greve, R., Koch, T., and Hutter, K.: Unconfined flow of granular avalanches along a partly curved surface, in: P. Roy. Soc. London A, 445, 399-413, 1994.

Iverson, R. M. and Denlinger, R. P.: Flow of variably fluidized granular masses across three.dimensional terrain -1 : Coulomb mixture theory, J. Geophys. Res., 106(B1), 537-552, 2001.

Jakob, M. and Hungr, O.: Introduction: Debris-flow hazards and related phenomena, edited by: Jakob, M. and Hungr, O., Praxis, Springer Verlag, Berlin and Heidelberg, Germany, 1-8, 2005.

Julien, P. and Lan, Y.: Rheology of hyperconcentrations, J. Hydrol. Eng., 117(3), 346-353, 1991.

Koch, T., Greve, R., and Hutter, K.: Unconfined flow of granular avalanches along a partly curved chute. II. Experiments and numerical computations, In: P. Roy. Soc. London A, 445, 415-435, 1994.

Mangeney, A., Vilotte, J. P., Bristeau, M. O., Perthame, B., Bouchut, F., Simeoni, C., and Yerneni, S.: Numerical modelling of avalanche based on saint Venant equations using a kinetic scheme, J. Geophys. Res., 108(B11), 2527, doi:10.1029/2002JB002024, 2003.
McDougall, S. and Hungr, O.: Objectives for the development of an integrated three-dimensional continuum model for the analysis of landslide runout, in: Proceedings of the 3rd. International Conference on Debris Flows Hazard Mitigation, Mechanics, Prediction and Assessment, Davos, Switzerland, 10-12 September 2003, 481-490, 2003.

McDougall, S. and Hungr, O.: Dynamic modelling of entrainment in rapid landslides, Can. Geotech. J., 42(5), 1437-1448, 2005.

McDougall, S., Pirulli, M., Hungr, O., and Scavia, C.: Advances in landslide continuum dynamic modeling (Special Lecture), 10th International Symposium On Landslides And Engineered Slopes, Xi' An, China, 30 June-4 July, 835-841, 2008.

Naef, D., Rickenmann, D., Rutschmann, P., and McArdell, B. W: Comparison of flow resistance relations for debris flows using a one-dimensional finite element simulation model, Nat. Hazards Earth Syst. Sci., 6, 155-165, 2006, http://www.nat-hazards-earth-syst-sci.net/6/155/2006/.

O'Brien, J. S., Julien, P. Y., and Fullerton, W. T.: Two-dimensional water flood and mudflow simulation, J. Hydrol. Eng., 119(2), 244-261, 1993.

Pirulli, M.: Numerical modelling of landslide runout, a continuum mechanics approach, Dissertation, Politecnico di Torino, Torino, Italy, 2005.

Pirulli, M. and Sorbino, G.: Effetto della reologia sull'analisi della propagazione di flussi di detrito, Incontro Annuale dei Ricercatori di Geotecnica, CD-ROM, 2006.

Pirulli, M., Bristeau, M. O., Mangeney, A., and Scavia, C.: The effect of earth pressure coefficient on the runout of granular material, Environ. Modell. Softw., 22(10), 1437-1454, 2007.

Pirulli, M. and Mangeney, A.: Results of back-analysis of the propagation of rock avalanches as a function of the assumed rheology, Rock Mech. Rock Eng., 41(1), 59-84, 2008.

Revellino, P., Hungr, O., Guadagno, F. M., and Evans, S. G.: Velocity and runout simulation of destructive debris flows and debris avalanches in pyroclastic deposits, Campania region, Italy, Environmental Geology, 45, 295-311, 2004.

Rickenmann, D. and Koch, T.: Comparison of debris flow modelling approaches, in: Proceedings of the 1st Int. Conf. on Debris Flow Hazards Mitigation: Mechanics, Prediction, and Assessment, ASCE, Reston, VA, USA, 576-585, 1997.

Rickenmann, D.: Empirical relationships for debris flows, Natl. Hazards, 19(1), 47-77, 1999.

Rickenmann, D.: Runout prediction methods, in: Debris-flow Hazards and Related Phenomena, edited by: Jakob, M. and Hungr, O., Springer Praxis, Heidelberg, Germany, 305-324, 2005.

Rickenmann, D., Laigle, D., McArdell, B. W., and Hubl, J.: Comparison of 2D debris-flow simulation models with field events, Computational Geosciences, 10, 241-264, 2006.

Savage, S. B. and Hutter, K.: The motion of a finite mass of granular material down a rough incline, J. Fluid Mech., 199, 177-215, 1989.

Wieland, M., Gray, J. M. N. T., and Hutter, K.: Channelized freesurface flow of cohesionless granular avalanches in a chute with shallow lateral curvature, J. Fluid Mech., 392(73), 73-100, 1999.

Zimmermann, M., Mani, P., Gamma, P., Gsteiger, P., Heiniger, O., and Hunziker, G.: Murganggefahr und Klimaänderung: ein GISbasierter Ansatz, Schlussbericht NFP 31, ETH, Zurich, Switzerland, 161 pp., 1997. 